\title{
Intérpretes solitários
}

\author{
Paulo Eduardo Carvalho
}

Titulo: 0 ano do pensamento mágico (The Year of Magical Thinking, 2005). Autora: Joan Didion. Tradução: Pedro Gorman. Encenação: Diogo Infante. Cenografia e figurino: Catarina Amaro. Desenho de luz: Miguel Seabra. Música original: João Gil. Video: Pedro Macedo. Interpretação: Eunice Muñoz. Produção: Teatro Nacional D. Maria II. Local e data de estreia: TNDMII, 12 de Novembro de 2009. Local e data de apresentação no Porto: Teatro Nacional São João, 7-31 de Janeiro de 2010.

Titulo: Dois homens (1998). Autor: José Maria Vieira Mendes. Encenação: Carlos Pimenta. Cenografia: João Ribeiro. Música original: Dead Combo. Desenho de luz: José Carlos Nascimento. Interpretação: Ivo Alexandre. Produção: Teatro Municipal de Almada. Local e data de estreia: Teatro Municipal de Almada, 14 de Março de 2008. Local e datas de apresentação no âmbito do ciclo "Solos": Teatro Carlos Alberto, Porto, 8-10 de Janeiro de 2010.

Titulo: A febre (The Fever, 1990). Autor: Wallace Shawn. Tradução: Jacinto Lucas Pires. Encenação: Marcos Barbosa. Cenografia: F. Ribeiro. Figurinos: Susana Abreu. Desenho de luz: Pedro Carvalho. Interpretação: João Reis. Produção: Teatro Oficina. Local e data de estreia: Centro Cultural Vila Flor, Guimarães, 29 de Abril de 2009. Local e datas de apresentação no âmbito do ciclo "Solos": Teatro Carlos Alberto, Porto, 14-17 de Janeiro de 2010.

Titulo: Amor (1998). Autor: André Sant'Anna. Encenação: Marcos Barbosa. Desenho de luz: Pedro Carvalho. Interpretação: Flávia Gusmão. Produção: Teatro Oficina. Local e data de estreia: Espaço Oficina, Guimarães, 17 de Dezembro de 2008. Local e datas de apresentação no âmbito do ciclo "Solos": Teatro Carlos Alberto, Porto, 21 de Janeiro de 2010.

Título: Concerto à la carte (Wunschkonzert, 1973). Autor: Franz Xavier Kroetz. Tradução: Maria Adélia Silva Melo. Encenação: Rui Madeira. Cenografia: Carlos Sampaio. Figurinos: Silvia Alves. Desenho de som: Pedro Pinto. Desenho de luz: Fred Rompante. Interpretação: Ana Bustorff. Produção: Companhia de Teatro de Braga. Local e data de estreia: Theatro Circo, Braga, 31 de Março de 2008. Local e datas de apresentação no âmbito do ciclo "Solos": Teatro Carlos Alberto, Porto, 28-31 de Janeiro de 2010.

Titulo: Electra. Dramaturgia, selecção musical e figurino: Olga Roriz e Paulo Reis. Direcção de ensaios e cenografia: Paulo Reis. Desenho de luz: Clemente Cuba. Desenho de som e pós-produção áudio: Sérgio Milhano. Interpretação: Olga Roriz. Produção: Companhia Olga Roriz, OPART, TNSJ. Local e data de estreia: Teatro Camões, 28 de Janeiro de 2010. Local e datas de apresentação no âmbito do ciclo "Solos": Teatro Nacional São João, 4-7 de Fevereiro de 2010.

Titulo: $O$ livro do desassossego. Autor do libreto (a partir de Fernando Pessoa/Bernardo Soares), música, concepção cénica, guião e realização do video: Michel van der Aa. Cenografia: Marc Warning. Desenho de luz: Marc Heinz. Som: Paul Jeukendrup. Interpretação: Remix Ensemble, João Reis e Ana Moura (participação especial no video). Produção: LINZ09 European Cultural Capital, ZaterdagMatinee, Fonds voor de Scheppende Toonkunst, com o apoio da Casa da Música. Local e data de estreia da versão portuguesa: Casa da Música, Porto, 9 de Fevereiro de 2010.

Titulo: Vulcão (2009). Autor: Abel Neves. Encenação: João Grosso. Cenografia: Rui Alexandre. Figurinos: Dino Alves. Desenho de luz: José Nuno Lima. Sonoplastia: Luis Aly. Interpretação: Custódia Gallego. Produção: TNDMII e ACE/Teatro do Bolhão. Local e data de estreia: Teatro Nacional D. Maria II, 26 de Novembro de 2009. Local e data de apresentação no Porto:Teatro do Bolhão, 19 de Fevereiro - 7 de Março de 2010.

Titulo: Terra sem palavras (Land ohne worte, 2007). Autora: Dea Loher. Encenação: João Cardoso. Cenografia: Sissa Afonso. Figurinos: Bernardo Monteiro. Desenho de luz: Nuno Meira. Sonoplastia: Francisco Leal. Produção: ASSéDIO. Local e data de estreia: Estúdio Zero, Porto, 27 de Março de 2010.

A verdade é que todos nós praticamos a arte do monólogo, uns mais do que outros, mais em murmúrio uns do que outros, uns mais capazes de se fazerem ouvir, muitos irremediavelmente perdidos no enigma deste mundo. 


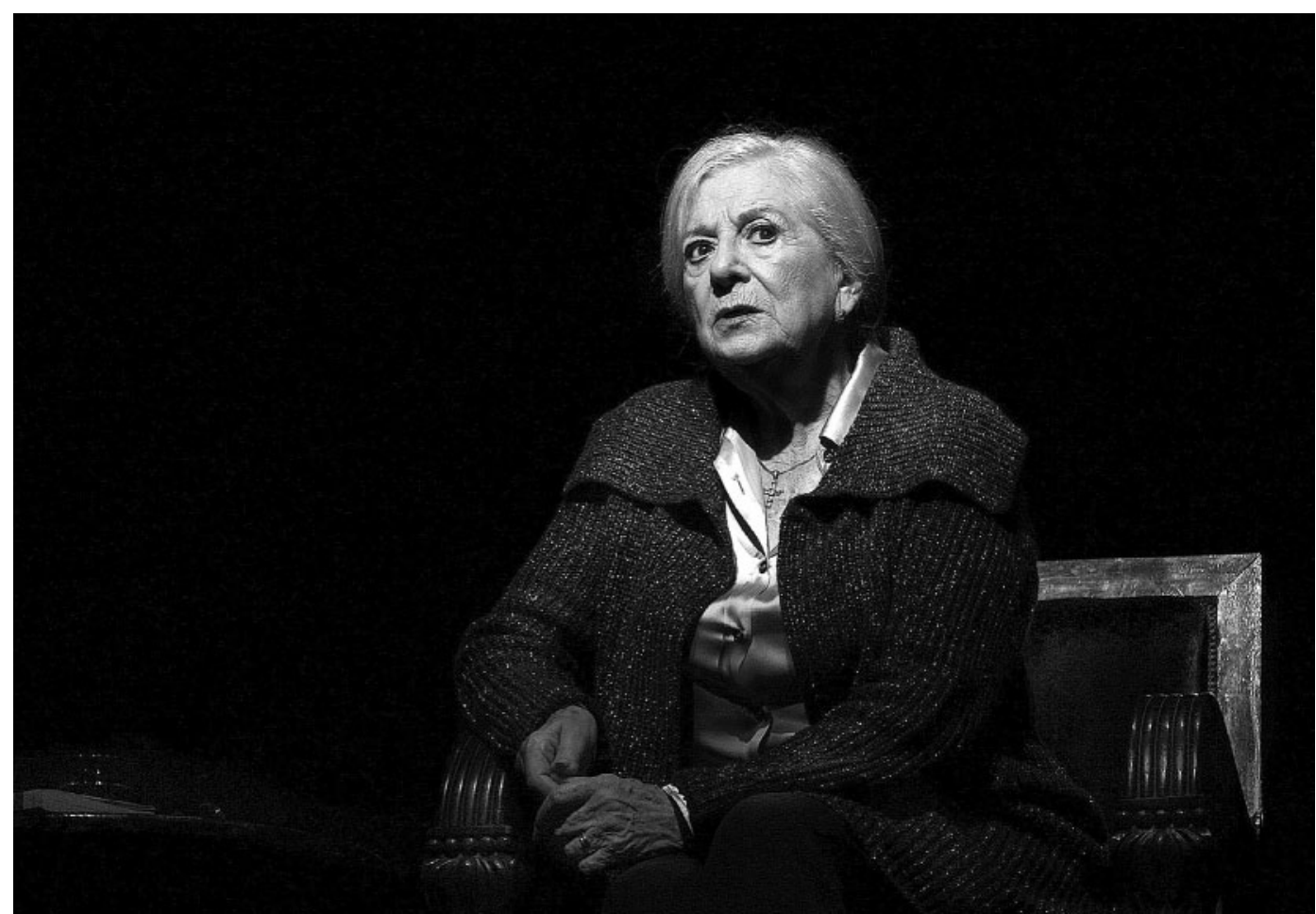

Algumas recentes iniciativas portuguesas têm contribuido para dar uma invulgar visibilidade ao monólogo teatral. Um primeiro exemplo é a produção, pelo Teatro Nacional D. Maria II, de um espectáculo que contava unicamente com a presença da actriz Eunice Muñoz, 0 ano do pensamento mágico, da norte-americana Joan Didion. Exemplo diverso e mais abrangente é Solos, ciclo de cinco espectáculos para cinco intérpretes programado pelo Teatro Nacional São João: Dois homens (Ivo Alexandre), A febre (João Reis), Amor (Flávia Gusmão), Concerto à la carte (Ana Bustorff) e Electra (Olga Roriz). 0 Teatro do Bolhão, que já em 2006 tinha co-produzido o extraordinário Começar a acabar com João Lagarto, propôs mais recentemente a estreia absoluta de um monólogo escrito por Abel Neves, Vulcão, interpretado por Custódia Gallego. A ASSéDIO prosseguiu a sua pesquisa da forma monológica com um texto da alemã Dea Loher, Terra sem palavras, que teve Rosa Quiroga como intérprete. A Casa da Música, no Porto, associou-se à produção e programou um espectáculo musical e cénico a partir d'O livro do desassossego, de Fernando Pessoa / Bernardo Soares, com interpretação de João Reis. Outros exemplos incluem ainda o facto de Júlio Cardoso ter decidido celebrar os seus cinquenta anos de carreira com Eu sou a minha própria mulher, um monólogo de Doug Wright, encenado por João Mota, ou os seis espectáculos programados pela Escola da Noite, em Coimbra, no âmbito do ciclo Do monólogo, coisa pública (1 e 6 de Março de 2010), ou ainda o "festival de monólogos" subordinado ao título Cabeças falantes, que decorrerá no Clube Estefânia, em Lisboa entre Maio e Dezembro deste mesmo ano.

Em resumo, este tem sido um periodo particularmente fértil na exploração de uma forma que, com este grau de independência e reconhecimento, se pode considerar ainda "jovem" na história do teatro ocidental. Claro que é possivel encontrar em determinados períodos do nosso património dramatúrgico importantes momentos monológicos. Bastará pensar nos clássicos gregos, em Shakespeare ou na tragédia neoclássica francesa para reconhecer a importância do solilóquio, que acabaria, mais tarde, por ser menos tolerado pelo modelo realista e naturalista. Contudo, a partir de finais do século XIX e inícios do XX, a forma monológica conquistaria uma expressão que as últimas décadas só têm contribuido para reforçar.

Embora, por vezes, ainda encarado com alguma suspeição, como se fosse uma forma menor, só praticada por jovens dramaturgos em cursos de escrita criativa, 0 facto é que o monólogo se estabeleceu como uma poderosa estrutura dramática, a ponto de Jean-Pierre Sarrazac reconhecer: "A intrusão devastadora do monólogo no território do diálogo dramático (...) é a prova de que a luta em curso é contra a homogeneidade da língua de teatro. Na verdade, trata-se menos de consagrar o monólogo como forma hegemónica do texto moderno e mais de instituir a heterogeneidade nas formas da linguagem" (1999: 136). 0 monólogo tem-se revelado uma forma particularmente apta para a revelação da "artificialidade" da representação teatral, algo que parece ir de encontro à tendência (auto-)reflexiva nas artes de todo o século XX. Além disso, não é possivel falar do monólogo como uma forma rígida e limitada, sendo mais correcto insistir na sua pluralidade, nos tipos radicalmente diferentes de monólogos teatrais, tantas são as suas combinações possíveis, através do uso de uma única personagem ou de diversas personagens, de uma única acção ou múltiplas acções, dando assim origem a infinitas variações.

Estas experiências com o formato monológico têm também permitido explorar o seu potencial social e político e, ao mesmo tempo, promover as dimensões intrinsecamente literárias da forma, isto é, a própria tessitura textual da ficção dramática. É importante também não esquecer a qualidade híbrida do monólogo, a sua particular aptidão para combinar o dramático com o lírico e o narrativo. Tendo reemergido no contexto de preocupações muito 


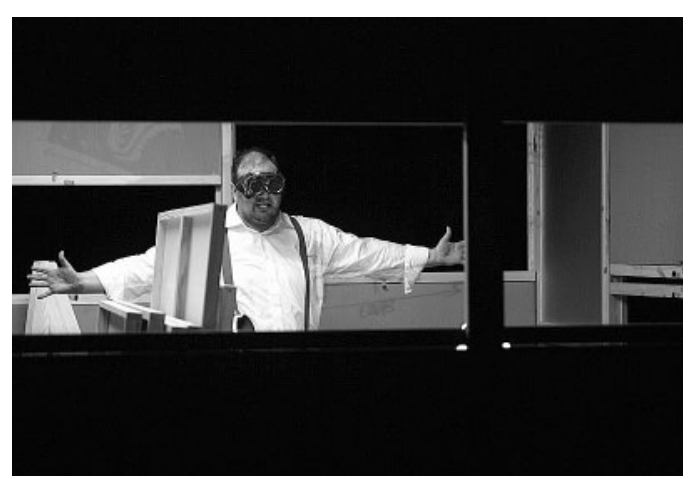
mental das personagens, até ao reconhecimento da
dificuldade, se não mesmo da impossibilidade de expressão
da identidade através da linguagem, como os "monodramas"

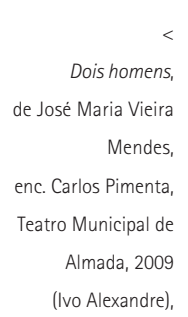 \\ fot. Da Maia Nogueira. \\ A febre, \\ de Wallace Shawn enc. Marcos Barbosa, \\ Teatro Oficina, 2009 \\ (João Reis), \\ fot. Pedro Vieira de \\ Carvalho.} parece ser particularmente interessante nas qualidades e
potenciais dramatúrgicos do monólogo é precisamente esta aparente contradição entre uma forma concentrada como nenhuma outra na exploração do eu - aquilo que Joseph Danan (1995) chama a "encenação do pensamento" - e uma capacidade rara de reflexão prismática do mundo. enc. Marcos Barbosa

Teatro Oficina, 2008 (Flávia Gusmão), Esta tensão entre a profunda concentração numa demanda subjectiva e o empenhamento no mundo mais vasto é uma das dimensões mais produtivas da forma monológica. Num outro estudo sobre as formas "intimas" do teatro, JeanPierre Sarrazac interrogava-se sobre a possibilidade de "um teatro em que o psiquismo e o mundo seriam vasos comunicantes" (1989: 10).

Uma outra tensão importante é aquela que se prende com a própria incidência cénica do monólogo: se, por um lado, o texto dramático monológico surge habitualmente dotado do que poderiamos descrever como uma "textualidade densa", próxima da intensidade literária, por outro, todo o exercício de transmissão dessa matéria dependerá sempre de um tipo muito particular de concentração e de energia interpretativa, sem as quais as palavras dificilmente conseguirão sair da página para se transformarem num acontecimento vivo e partilhado. Esta reflexão reconduz a questão para o domínio do virtuosismo que é exigido ao intérprete solitário, que tem no palco ou no público o seu único interlocutor. Numa das reflexões sobre o monólogo que integram o magnífico programa de Solos editado pelo TNSJ, Regina Guimarães fala, com penetrante sugestão, no "fingimento de (se) estar só, / de ninguém estar a escutar", para mais adiante acrescentar: "No monólogo teatral, / a mentira ainda pode ser mais verdade / e mais contraditoriamente mentira" (2010: 4).

0 espectáculo 0 ano do pensamento mágico produzido pelo TNDMII, mas com o qual o TNSJ, de algum modo, abriu o seu ciclo de "intérpretes solitários" - é um magnífico exemplo de como a expressão da mais perturbada e perturbadora interioridade surgia comprometida pela sua inscrição num mundo estranho ao espectador português. 0 universo social e cultural em que Joan Didion - trata-se, afinal, de um relato autobiográfico - se move, que refere e nomeia ao longo de um discurso de questionável elaboração dramatúrgica, apresentava o
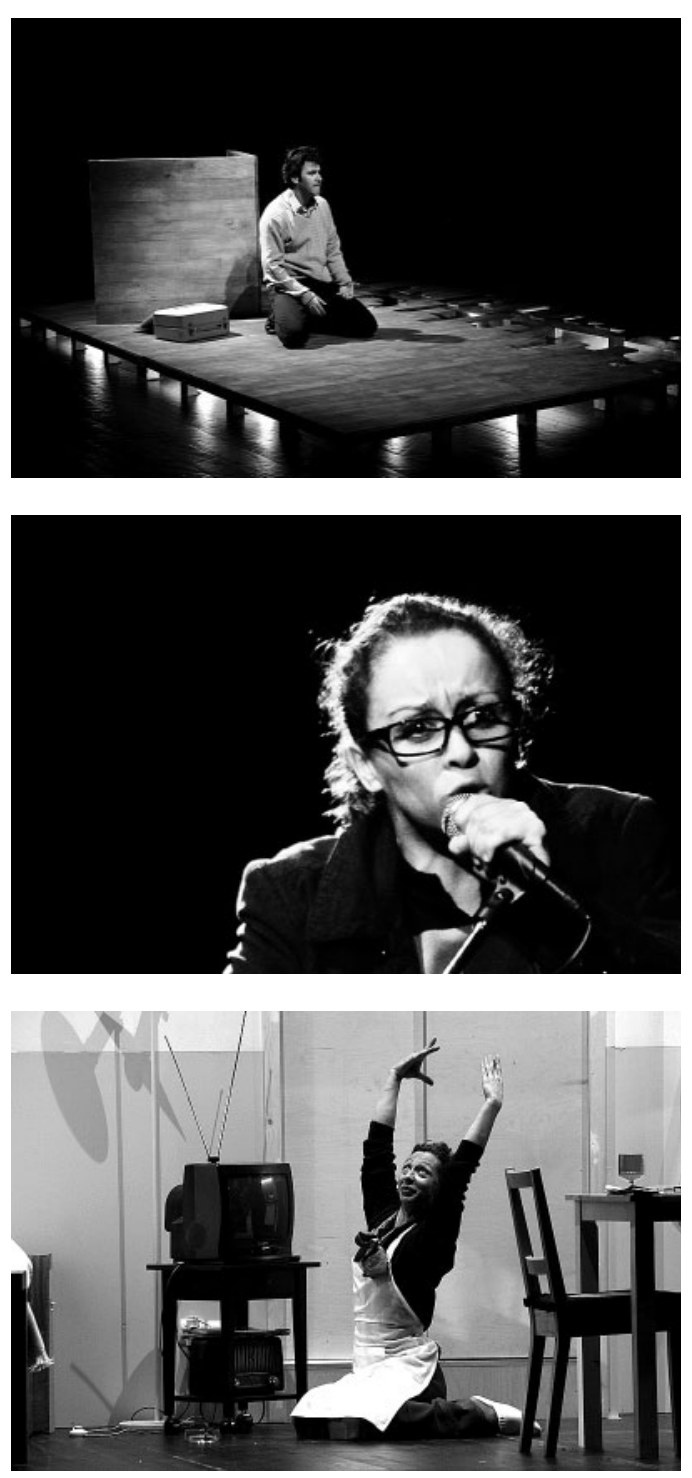

desagradável efeito de alienar o espectador de um conjunto de experiências que só a poderosa intuição expressiva da intérprete parecia compensar, na compreensão justa de que todo o trabalho teria que se realizar na ausência de uma verdadeira "personagem". Embora limitada pelo encenador ao espaço de uma cadeira e prejudicada por um dispositivo cenográfico desproporcional e estilisticamente desajustado relativamente ao jogo interpretativo, Eunice Muñoz conseguia emprestar a todo o exercício a medida necessária de intimidade e de cumplicidade para justificar o alcance de uma reflexão ambiciosa sobre questões tão transversais à nossa comum humanidade como a doença e a morte, o amor e a ausência, o acaso e a coincidência.

Dois homens adapta e reescreve diversos textos de Frank Kafka em torno de uma ficção: um homem fechado no seu escritório, rodeado pelos seus papéis. Tal como o espectáculo de 1998, com Luís Gaspar, produzido pelos Artistas Unidos, tornava claro, tratou-se de um início promissor para José Maria Viera Mendes, sobretudo pelo cuidado tratamento dado à linguagem como matéria de teatro, plástica e sonora. Esta revisitação, agora encenada por Carlos Pimenta e interpretada por Ivo Alexandre, aposta numa justa metáfora cenográfica (de João Mendes Ribeiro): a estrutura de uma caixa, rodeada pelos espectadores por 


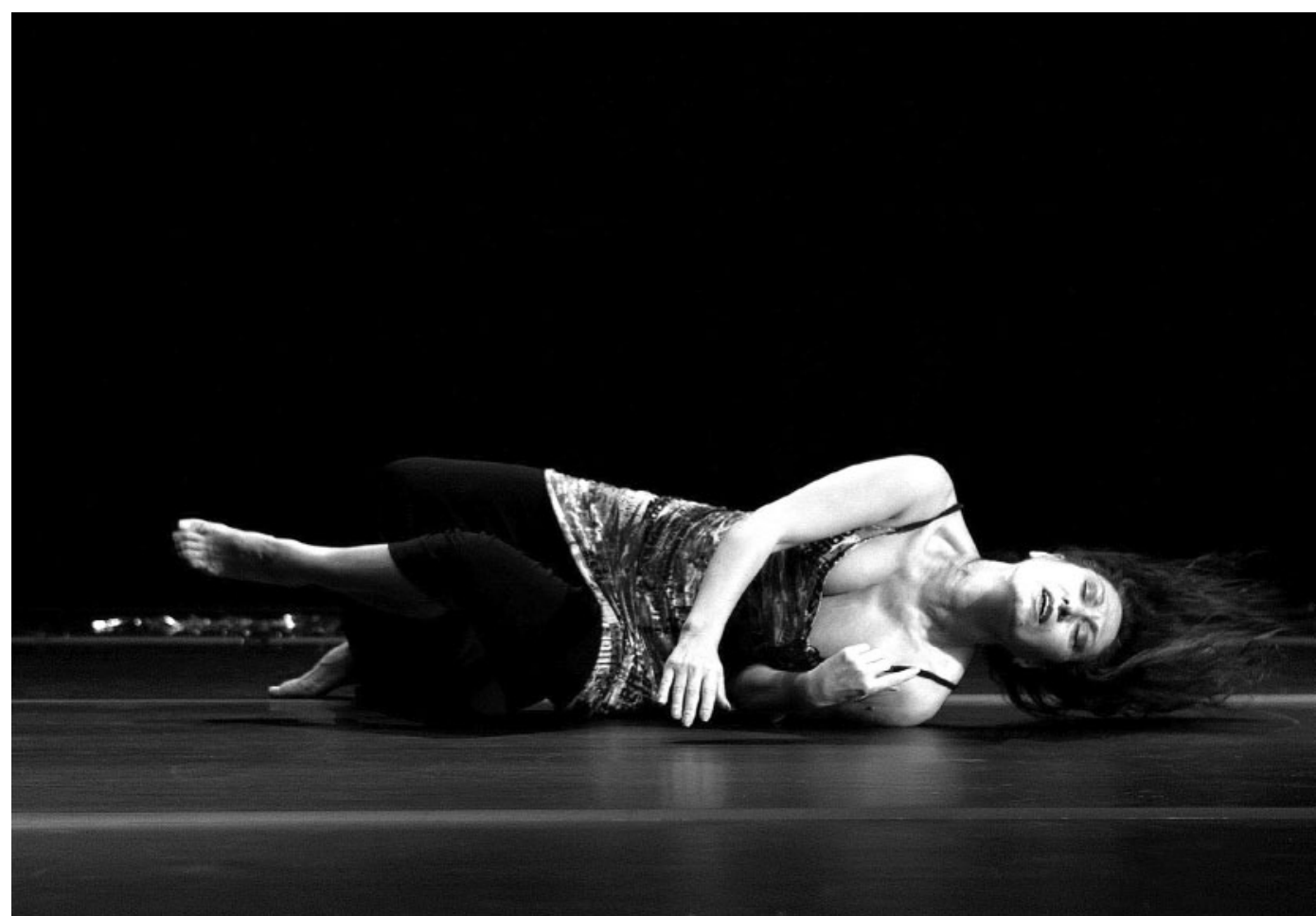

todos os lados, que, ao longo dos 50 minutos de duração do espectáculo, o intérprete vai preenchendo através da colocação de painéis que progressivamente ocultam a sua presença e o aprisionam no escritório a que se resume 0 seu mundo. É uma ideia aliciante que apresenta, contudo, como desvantagem uma excessiva ocupação física do intérprete e, consequentemente, uma desagradável distracção do espectador relativamente à matéria mais importante, que são mesmo as palavras que, por si, funcionam já como prisão bastante para a personagem. Ivo Alexandre empresta à sua interpretação uma expressiva fisicalidade que, como já se sugeriu, tem como único óbice deslocar excessivamente a atenção da matéria dramática para a sua, talvez, por demais elaborada representação.

A febre, do norte-americano Wallace Shawn, é um texto esplêndido, uma portentosa exploração das muitas possibilidades abertas pelas forma monológica, enquanto relato confessional da culpa que assalta um ocidental de meia-idade face às múltiplas inumanidades que assolam o nosso mundo e ao próprio lugar e função da arte perante tal cenário de devastação e injustiça. Tem, além do mais, o impeto compulsivo de um texto que foi originalmente escrito para ser interpretado pelo próprio autor. João Reis é um actor extraordinário, que preserva e dá recorte a cada frase e a cada palavra com uma correcção e uma urgência expressiva, vocal e física, absolutamente ímpares. Num dispositivo cenográfico discreto, subtilmente marcado por uma fractura, Marcos Barbosa ajudou a desenhar uma experiência inesquecivel de teatro político, só talvez limitada pelo recorte excessivamente "composto" do próprio intérprete, cujas características se adequam com dificuldade a uma imagem mais perturbadora daquela espécie de torturada inadequação sugerida pelo texto de Shawn.

Encenado pelo mesmo Marcos Barbosa, Amor é a audaciosa passagem para o palco de um texto originalmente não dramático de André Sant'Anna. Através de uma arriscada aposta no recurso ora ao sotaque brasileiro ora à pronúncia portuguesa, um mecanismo exemplarmente assegurado pela interpretação de grande virtuosismo e intensidade de Flávia Gusmão, o espectáculo dava literalmente a ver e a sentir o maravilhoso trabalho sobre a língua portuguesa empreendido pelo escritor brasileiro, amplamente justificando esta adaptação à cena. Na verdade através da alternância de diferentes atitudes e registos discursivos e tirando partido de suportes vários de amplificação sonora, o espectáculo dá corpo a um magnífico trabalho de invenção linguistica e de estruturação retórica.

Concerto à la carte, o texto do alemão Franz Xaver Kroetz, foi talvez o espectáculo mais decepcionante deste ciclo, não tanto pela matéria dramática, extraordinária trata-se, afinal, de uma longa didascália, que obriga a sua intérprete ao exercício do silêncio e a uma exigente eloquência física -, mas antes pelas discutiveis opções dramatúrgicas envolvidas na actualização de uma ficção estrangeira e já antiga (1973). Refira-se, neste caso, o recurso ao Preço certo televisivo e ao Paixões cruzadas radiofónico que se tornam numa fonte de distracção, quando deveriam ser parte integrante da silenciosa mas poderosa ficção dramática, e as desacertadas opções cenográficas, na medida em que na configuração do espaço faltou, sobretudo, a expressão do vivido e do usado, essencial para veicular a tragédia dos gestos quotidianamente repetidos. No corajoso e competente trabalho físico da intérprete, sentiu-se ainda a ausência da componente tragicómica, à maneira de um Buster Keaton, capaz de tornar eloquente a aparente inexpressividade e um mais minimal repertório gestual. Por anacronismo ou desacerto, perdeu-se, assim, o impacto político de um realismo diferente: e fiquei a pensar no exemplo da Miss Lonelyhearts da Janela indiscreta, de Hitchcock...

Vinda de outro universo e de outras linguagens, a Electra de Olga Roriz apresenta-se como um austero, mas "tremendo", exercicio de metateatralidade: toda a proposta deste extraordinário solo assenta no jogo de uma intérprete 
Vulcão,

de Abel Neves,

enc. João Grosso,

ACE/Teatro do Bolhão

TNDMII, 2009

(Custódia Gallego),

fot. Ana Pereira

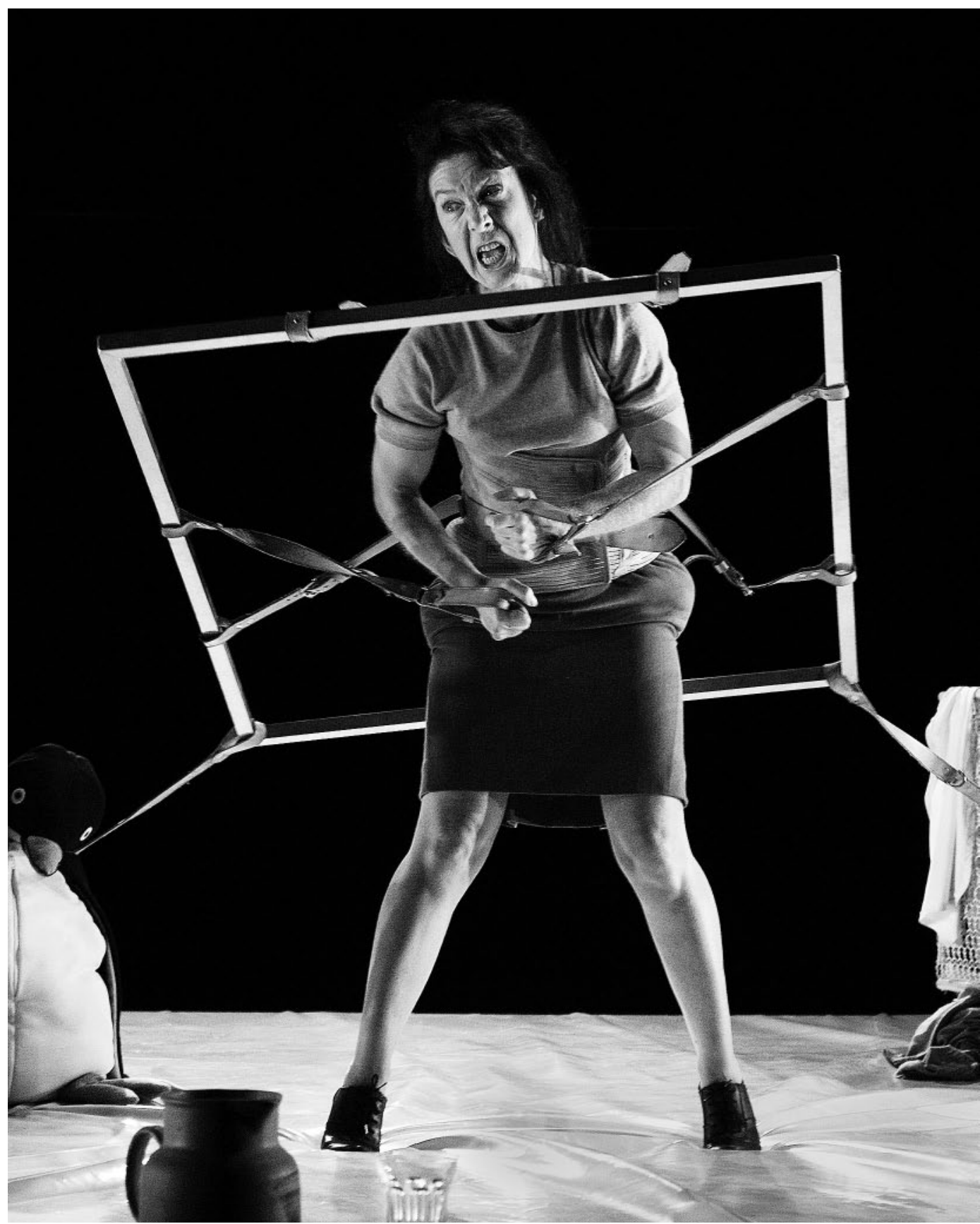

que, com óbvia inquietação, se entrega, a espaços, à corporização da dor, através de uma dinâmica expressiva fragmentada e descontínua. Todo o espectáculo é feito de cenas soltas, de frases coreográficas que pouco mais do que indiciam ou apontam para possibilidades que nunca são mais amplamente desenvolvidas, mas que deixam sempre um rasto de força e de intensidade absolutamente invulgares. Deslocando-se no vazio do palco, Olga Roriz funciona como a figuração perfeita de uma intérprete que, em processo, busca um corpo para as forças que, alternadamente, a habitam. Entre a aparente ausência expressiva e o sublime interpretativo, este é um diverso exercício do silêncio, e se alguma coisa pareceu a mais fo talvez um recurso excessivo, porque desnecessário, a uma banda sonora, por vezes, redundante - excepção feita ao extraordinário momento final, com o recurso à Electra de Richard Strauss.
Em resumo, pode dizer-se que o ciclo Solos funcionou como a amostra possivel de uma ampla variedade de formas monológicas, com a expressão cénica do silêncio, ora especificamente teatral, no caso de Concerto à la carte, ora mais ostensivamente coreográfico, no caso de Electra. Mas essa variabilidade é ainda visível na oscilação entre textos escritos propositadamente para a cena ou a ela adaptados entre a confessionalidade combinada com o compromisso político mais explícito d'A febre, o exercício mais distanciado das variações provocantes em torno da carne de Amor e a ficção obsessiva de Dois homens. Pela sua complexidade e pela diversidade de propostas, tratou-se de uma gesto programático que teria amplamente merecido uma iniciativa paralela em que criadores e críticos ou investigadores pudessem ter partilhado experiências e pontos de vista.

Quase contemporânea deste ciclo foi a estreia em Lisboa e, depois, a apresentação no Porto, no espaço do auditório 


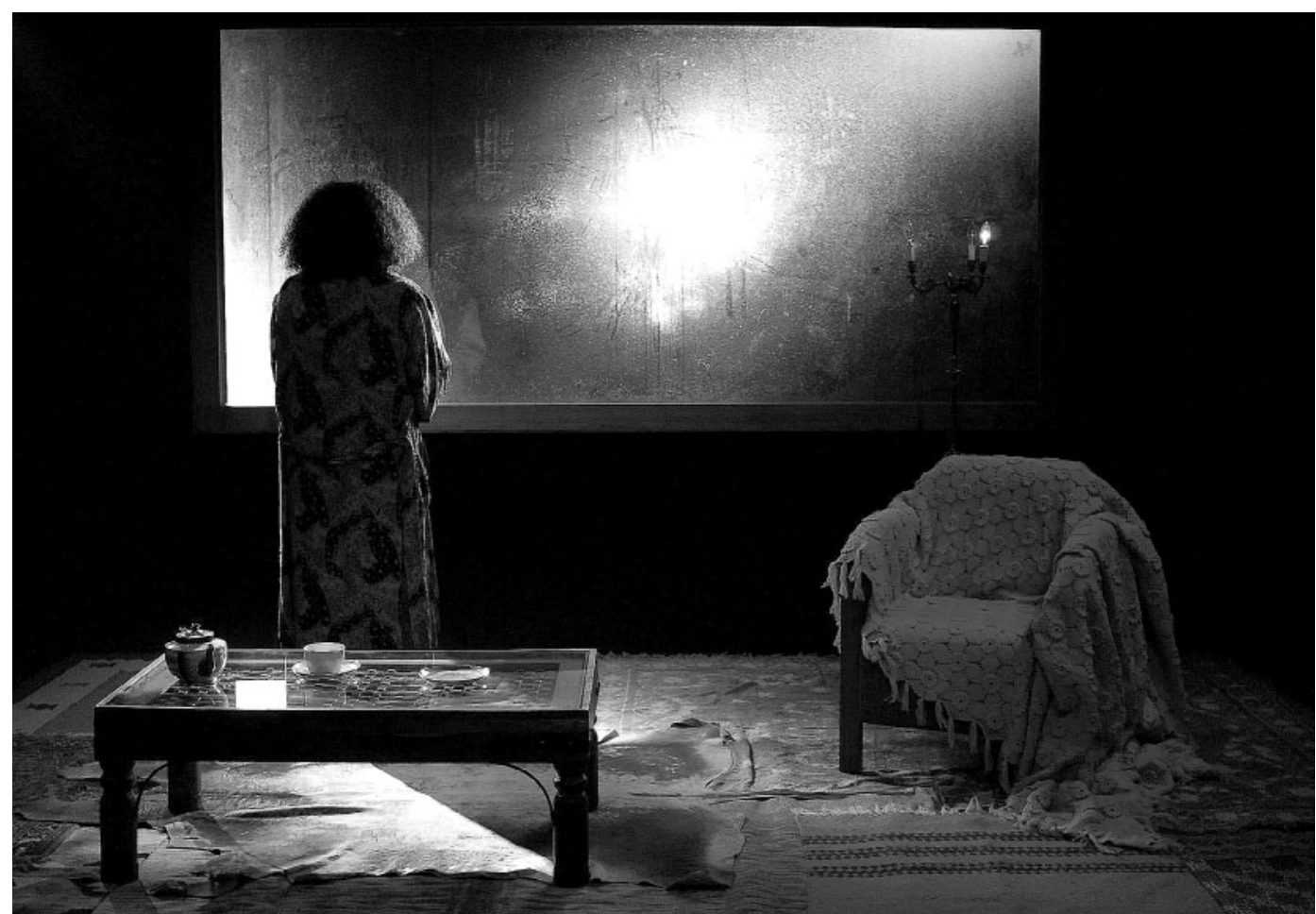

Terra sem palavras, de Dea Loher, enc. João Cardoso, ASSéDIO, 2010 (Rosa Quiroga), fot. Ana Pereira. da ACE/Teatro do Bolhão, de um dois mais recentes textos de Abel Neves. 0 Vulcão é o relato tenso e tumultuado de uma mulher, Valdete, que durante longos anos conhece a experiência da infelicidade e do sofrimento e que o TNDMII, em boa hora, disponibilizou na colecção de textos dramáticos que tem vindo a editar com notável regularidade. A peça corresponde ao modelo que poderiamos descrever como já clássico de um ser torturado e abusado que encontra no registo monológico a expressão para a sua existência turbulenta. Socorrendo-se de uma ampla variedade de registos, o dramaturgo constrói uma ficção por onde passam os mais diversos estados de alma e o relato das mais inimagináveis ignomínias. A cenografia de Rui Alexandre e a encenação de João Grosso caracterizam-se por algum excesso de gestos e soluções, contribuindo, de algum modo, para a menorização da importância do próprio discurso e, ao mesmo tempo, para a dissipação da energia interpretativa de Custódia Gallego, a actriz que generosamente se entrega a este exercicio.

A ASSéDIO é uma das companhias portuguesas que mais tem explorado as virtualidades da forma monológica, como comprovam muitas das suas produções ao longo dos últimos dez anos: O fantástico Francis Hardy, Curandeiro (2000), Rum e vodka e Uma noite em Novembro (2003), Billy e Christine e Testemunha (2004), Ossário (2005), os beckettianos [Sobressaltos] e Todos os que falam (2006), O produto (2007) e Terminus (2008), numa paleta repertorial sobretudo concentrada em propostas recentes da dramaturgia irlandesa. Desta vez a incursão foi na dramaturgia alemã contemporânea, através de um perturbador texto de Dea Loher, revelada ao público português em 2008, com a produção de Imaculados, pelo Novo Grupo - Teatro Aberto. Num espaço reduzido, delimitado por um chão de tapetes e uma enigmática superficie escura e espelhada ao fundo da cena, iluminada de modo a confundir-se ora com uma janela ou um quadro de ardósia, Rosa Quiroga dá voz a uma pintora atormentada pelo alcance e sentido da sua própria intervenção criativa após o confronto com a dura realidade com que se deparou na cidade de K. Teatro político no mais fundo sentido do termo, porque coloca as interrogações sobre o nosso mundo no quadro da própria subjectividade, Terra sem palavras é um texto cuja construção fragmentada e elíptica coloca sérios desafios interpretativos, resolvidos neste espectáculo com apurada subtileza e sentido de medida na gestão daquilo que é visualmente indispensável para garantir a escuta mais apurada.

Experiência completamente diversa daquelas até aqui recenseadas foi 0 livro do desassossego, o estimulante espectáculo músico-cénico criado por Michel van der $\mathrm{Aa}$ e apresentado na Casa da Música. Não se trata, na verdade, de uma nova instância de interpretação solitária, na medida em que aqui o actor que dá voz e corpo ao heterónimo pessoano partilha a cena com uma orquestra de câmara e a projecção em múltiplos suportes de um filme, situação que o obriga a uma esforçada e rigorosa articulação das suas intervenções. João Reis revela-se, mais uma vez, um intérprete de excepção, na gestão dessa difícil mas poderosa interacção expressiva, erguendo um Bernardo Soares talvez um pouco mais histriónico do que a personagem que 0 leitor poderá construir com base na leitura da obra, mas sem dúvida coerente com toda a complexa proposta do espectáculo - que teria sido mais justo na escolha de um outro título que melhor sugerisse a visão selectiva e muito particular do compositor, realizador e encenador holandês sobre um tão vasto e complexo universo.

\section{Referências bibliográficas}

DANAN, Joseph (1995), Le Théâtre de la pensée, Rouen, Éditions Médianes. GUIMARÃES, Regina (2010), "Monologando", in programa de Solos, Porto, TNSJ, pp. 4-5.

SARRAZAC, Jean-Pierre (1989), Théâtres intimes, Arles, Actes Sud. - - (1999), L'Avenir du drame, Paris, Circé. 